\title{
SAT Treatment Guidelines for Sick Children: A Santhosh Kumar (ed.)
}

\author{
Published by Paras Medical Publishers (P) Ltd., New Delhi, India; 5th Edition; 2019; \\ ISBN: 978-81-8191-503-0; Pages: 487; Price: Rs. 495/-
}

\section{Jayashree ${ }^{1}$ (D)}

Received: 14 August 2019 / Accepted: 14 August 2019 / Published online: 29 August 2019

(C) Dr. K C Chaudhuri Foundation 2019

The 5th edition of the book "SAT Treatment Guidelines for Sick Children" is a revised and updated version of the previous edition with some new additions. This book will serve as a ready reckoner for postgraduate students and practising pediatricians during their day-to-day management of sick children. In the era of super specialisation, a book addressing all systems and their common problems is a welcome change to sensitise postgraduates and practising pediatricians alike. Overall there are 14 chapters divided systemwise and each chapter deals with the most common problems encountered within that system. The chapter contents are presented in a simple, easy to understand language and emphasise the practical aspects. The monotony of continuous text has been broken with appropriately placed tables and algorithms. Each chapter is brief, highlighting mostly the broad approach rather than the concept. This will be beneficial in an emergency setting where postgraduates are looking for a ready reference on 'what to do' and 'how to do' rather than 'why to do'? At the end, the authors have included a chapter on important procedures and an appendix which contains important formulae, normal biological values at various ages, and composition of common fluids. A noteworthy inclusion is the list of sam- ples to be collected for vaccine preventable disease surveillance. This aspect tends to take a backseat in sick children and its inclusion will act as a reminder for postgraduates. The contributing authors have vast experience in clinical teaching and that is evident by the simplified manner in which the contents have been presented. However, certain lacunae need to be addressed by the authors in the next edition. In the era of evidence-based medicine, the concepts and treatment modalities constantly change and evolve. A more extensive literature search with relevant recent references for every chapter would have made this exercise more robust. It would have stimulated the young postgraduates to delve deeper. Similarly, certain treatments need to be updated as per current recommendations, for instance in Chapter 2, under management of SVT in infants, the authors mention carotid massage which is no longer recommended. Nevertheless, the book will fulfil its basic objective of being a handy guide for practising pediatricians and postgraduates.

Publisher's Note Springer Nature remains neutral with regard to jurisdictional claims in published maps and institutional affiliations.
M. Jayashree

mjshree@hotmail.com

1 Pediatric Emergency and Intensive Care Units, Advanced Pediatrics Centre, PGIMER, Chandigarh 160012, India 